\title{
The impact of fatigue on balancing in creating re-injuries in mountaineers with chronic ankle sprain
}

\author{
Himan Ebrahimi $^{1 *}$, Mehdi Shahrokhi ${ }^{1}$, Zahra Toktam Barmar ${ }^{2}$, Ramin Balouchi $^{2}$
}

1. Department of Sport Pathology and Corrective Exercise, Faculty of Physical Education and Sport Sciences, University of Allameh Tabatabai, Tehran, Iran

2. Department of Physical Education and Sports Science, Islamic Azad University of Mashhad, Mashhad, Iran

*Corresponding author: Tel: +98 9199512844 Fax: +98 -

Address: West Boulevard Azadi Stadium, Faculty of Physical Education and Sports Sciences Allameh Tabatabai University, Department of Pathology and corrective exercises

E-mail: ebrahimihiman@yahoo.com

Received; 2015/09/10 revised; 2015/11/13 accepted; 2015/12/16

\begin{abstract}
Introduction: Sensory-motor control and in general gaining balance will be impaired after an ankle injury and in fatigue situations. The aim of this research was to study the effect of exercise-based fatigue on static and dynamic balance in mountaineering athletes who were successful in returning to a suitable level of physical activity after an ankle sprain injury.

Materials and methods: 25 active mountaineering athletes between 20 and 40 years were recruited on a voluntary basis. 12 persons with severe ankle sprain in the past were selected as experimental group and 13 healthy mountaineering athletes were selected as control group. Because balance test measuring was under the influence of evaluation time; fatigue test measurement running on the treadmill was performed in 2 sessions. Changes or fluctuations in the pressure Center or static balance were evaluated by Sharpened Romberg balance test and dynamic balance was evaluated by stability time after side jumping (the first session) and the maximum distance in the balance test $\mathrm{Y}$ (second session) were evaluated in the pre-test and post-test immediately after fatigue resulted by running on a treadmill. Data were analyzed using covariance test.
\end{abstract}

Results: before fatigue condition, there were a few differences between the two groups in stability time while doing side jump test $(\mathrm{P}<0.014)$. After the fatigue and in balance test $\mathrm{Y}$ and stability time while doing side jump test; there were more differences $(\mathrm{P}<0.001)$. In this case, there was a similar increase on static swing in both groups. Fatigue was considerably reduced the static and dynamic postural control of the athletes who had a history of injury. Changes related to fatigue was significant in dynamic postural control in athletes with previous ankle sprain history.

Conclusion: Even after the successful return to sport for athletes with previous damages, abnormalities in sensory-motor control and balance may lead to an increase the risk of ankle re-injury.

Keywords: Ankle sprain, Balance, Fatigue, Mountain climbers

\section{Introduction}

Ankle joint is one of the most important fulcrum joint in our body. This joint plays a very important role in our normal daily activities. Ankle sprain is the most common injuries in sports and recreational activities (1). This can be seen in many sports such as soccer, basketball, volleyball and so on. This damage usually can't be cured completely and is reversible (2). Functional instability of ankle has been one of the clinical problems that often occur in athletes (3). Several 
mechanical and neuromuscular factors involved in this problem. Functional instability of this joint is described as a sudden emptying which is a mental feeling and usually is defined as a defects of internal deep sense and neuromuscular system (4). This damage can lead to at least 7 workouts miss or one race miss for the athlete (5).

Proprioception means the ability to feel or perceive the spatial position of the body without using eye movements (6). Condition sense receptors sense involves muscle spindle receptors, Golgi tendon organ and joint receptors which transfer the data related to this sense to the central nervous system (6). These receptors function is to create awareness of the status and balance of the body parts in relation to each other (7). In other words, Proprioception of movement is a general term that contains sensory input from the muscle spindle receptors, tendons and joints to determine the position and motion and direction, intensity and speed as well as joint measures (8).

Many factors have been studied as a risk factor for ankle injuries, yet still there is no consensus on this issue. Beynnonet al (2002) studies previous sprain ankle, gender, height, weight, superior members, the anatomical shape of foot and leg, ankle joint laxity and range of motion of the ankle as internal risk factors and factors predict ankle injury. Their results show that gender, height and weight, superior members, the anatomical shape of foot, joint laxity and dominant foot have no effect on ankle injuries. However, they reported that previous ankle sprain is a predictor of ankle re-injury. And also they concluded that using ankle brace is effective in reducing re-injury (9). Nelson et al (2007), suggested that the type of sports, the type of competition (practice or competition), the type of professional game level or players' skills and players' post are as part of the risk factors for ankle injuries but there was no evidence to show any relationship between ankle injuries height or weight or body mass (10). McKay et al (2001) noted that the three risk factors for ankle injuries include: a history of ankle injury that can increase the risk of damaging up to 5 times more than healthy subjects, wearing shoes with air cells on the heels that can increased the risk of damages up to 3/4 times than those who were wearing normal shoes, and lack of fitness and stretching before racing that can increase the risks up to $2 / 6$ times more than the others $(11,12)$.

Ankle sprain in athletes which occurs frequently can cause ankle performance problems and imperfection. These defects can have devastating impact on the athlete's activity (13). Kerry et al. studied the correlation between subjects in a series of functional-operational tests in relation to lower parts of the body. The results showed that there is a positive relationship between the instability of the ankle and functional defects in side jump test and the test of jumping in the form of Latin eight and injured persons in comparison to healthy individuals have limitations in doing these exercises (14).

Lauren et al and Youfac et al used various functional tests to conclude that people with a history of ankle sprains have deficient performance $(15,16)$. On the other hand, the results of Mann et al and Kerry et al show the relationship between previous ankle sprains and functional deficits but they are inconsistent. They believed that ankle sprain does not have a negative impact on real performance and people with a history of ankle sprain do not have any deficient dysfunction (17, 18). Most athletes who have had a previous injury of the ankle sprain are not aware of such hidden dysfunctional defect in their activities so they do not care about it. But this deficiency and chronic instability can reduce athletes' confidence while performance and sometimes cause re-injuries. This is more important for athletes in higher levels (2). According to this interpretation, it is very important to identify and measure the defects and 
limitations in people with a history of ankle sprain. It is also necessary to find an easy and cost-effective way to identify ankle functional defects to prevent further damages and also having a suitable plan for rehabilitation programs.

So, lack of precise studies and comprehensive researches in this field especially in mountaineering in our country, it seems necessary to find ways of measuring this defect and determine limitations in creating more ankle injuries in people with ankle sprain history. According to above mentioned points, the Necessity of such research is obvious .

\section{Materials and methods}

This is a quasi-experimental research and 25 mountaineering athletes participated in this study. All participants were selected voluntarily from participants of the training course which is held by Mountaineering Federation. Participants were divided into two groups: experimental group included 12 athletes with severe ankle sprain history and control group) included 13 healthy athletes .

Inclusion criteria for this study included severe ankle sprain in last 3 years which they could return to the exercises fully within 6 months without any complaints of pain, swelling, or instability in the ankle and ankle injuries except than ankle during the past 3 years. Back to sports criteria is at least 6 months, because Engebretsen et al findings show that the highest risk for re-injury in people with ankle sprain occurs in the first 6 months after injury. There was no ankle sprain in control group during the past 3 years and no reports of problems were mentioned about leg or ankle by them (19).

After selecting the persons and obtaining the informed consent of them; research information written form and personal information form including height, weight and age was provided and then was completed by athletes. Sharpened Romberg balance test was used to measure static balance and dynamic balance test of side jump test was used for measuring stability time (the first stage) and the maximum distance in the balance test $\mathrm{Y}$ (the second stage) in the pre-test and posttest immediately after fatigue creation on a treadmill.

Three measuring protocols were applied. Because of the complexity of the tests and a short time after exercise-based fatigue was needed; measurements were carried out randomly in two different time schedules. The first part was postural fluctuations in Romberg test and the stabilityin landing after a one way jump was the second part of measuring balance test Y. Balance tests before and immediately after exercise-based fatigue on treadmill was measured. Two efforts were considered for each measuring test. To prevent recovery, measuring was performed in less than 4 minutes after the protocol was performed. Participants performed all tests without shoes and barefoot.

Sharpened Romberg test: to measure static balance we used Sharpened Romberg test (reliability: with eyes open 0/90-0/91 and with eyes closed 0/76 - 0.77) (19). The implementation of this method is that the test subjects after the warm-up must stand in a way that both feet are on the line then one of them (dominant leg) will be put ahead of the other leg and then arms are crossed on chest be. The time that the test subject can keep this posture with eyes close and open must be recorded for his/her score (20).

Side jump test: this test is used for measuring power, speed, balance and rotational stability of the lower extremity with emphasis on control on one leg (21). The reliability of the test for healthy athletes is reported 0.97 by Ortiz (22). In order to do this test; test participant must jump a distance of $30 \mathrm{~cm}$ on the ground, which was marked by two parallel pieces of tapes, in back and forth for 10 times. The test participant records were recorded 
by a Catiga stopwatch with the accuracy of 0.01 seconds (21).

Balancing test Y: This test is based on the Star Balance Test which is called a valid test for evaluating dynamic balance by Gribble (23). Intra and inter-examiner reliability coefficient of the various criteria are 0.85 to 0.91 and 0.99 to 1.00 respectively and reliability coefficient for intra and inter-examiner for total score are 0.91 and 0.99 , respectively, according to Plisky reports (24). In this test, three directions (anterior, posterior- internal and posterior-external) are form a $\mathrm{Y}$ shape with the angles of 135, 135 and 90 degrees relative to each other. Test participants must practice this test four times to learn it. (Test participant with right foot as the dominant foot did this test counter clockwise and test participant with left foot as the dominant foot did this test clockwise). For implementation, test participant stood at the center of the device with his dominant foot and push the mobile part of it with the other foot (It was important that dominant foot must not move from the center of the device, do not lean on the other foot or test participant fall on the ground). Then test participant is asked to stand on his both feet. The distance of the moving part to the center of the device is called accessing distance. Test participant was asked to do this test 3 times and then examiner determined the access in every direction and then divided this number by foot length (in centimeter) and then multiply it by 100 to have access distance in terms of foot length percentage in every 3 directions. Total combined score of each of the test participant is gained by adding up all the numbers and dividing them by 3 (24).

Fatigue Protocol: total body fatigue was gained by running on treadmill and increasing the speed caused mental fatigue. This protocol started at the speed of $8 \mathrm{~km} / \mathrm{h}$ and then the speed of pacing was increased by $2 \mathrm{~km} / \mathrm{h}$ in every 3 minutes. Test participants were trained to run a long time and experiencing complete exhaustion and verbal encouragement was provided at the end of the run (25).

\section{Statistical analysis}

Statistical analysis was done on obtained information by using SPSS version 20 . Statistical methods used in this study included Kolmogorov-Smirnov test for evaluating normality of data distribution and covariance analysis for examining the difference between pre-test and post-test data. The study has a significant level of 0.05 .

\section{Results}

The aim of this study was to compare changes related to fatigue for sensorymotor control in healthy mountaineers and the other ones who are returned successfully to the previous level of activities related to the time before their ankle sprain injury. It was supposed that mountaineers with previous injuries has gained their normal performance levels and are selected as experimental group. There were no differences between the two groups in baseline conditions before fatigue. Dynamic control was significantly higher in experimental group and they show fatigue more obviously. This shows that sensory-motor control defect is not obvious without fatigue. However, these athletes intended in all sports activities successfully without any empty feeling under foot or loose foot. It seems that experimental group can develop successful approaches to compensate fatigue resulting changes and control the situation .

Fatigue resulted from running on treadmill can affect all situation control measurements negatively. This result is consistent with the findings of several studies in the field of static and dynamic balance disorders in fatigue situations. We discussed the relationship of fatigue in two groups by using the Sharpened Romberg test, side jump test and test $Y$. In side jump test, stability function of experimental group was influenced significantly and the 
statistical difference was significant $(\mathrm{P}=0.014)$. Similarly, fatigue related to reaching the distance in test $\mathrm{Y}$ was greater in experimental group with sprained ankle in comparison with control group. Group differences were not mentioned in the beginning, and only minor differences were observed for side jumps. These findings suggest that sensory-motor control deficits in ankle sprains groups are small and may remain undetected in regular situations but they will be revealed in the case of physical fatigue (26). Similar research study shows that test participants with sprained ankle in their history can available distances before fatigue in comparison with after fatigue in test $\mathrm{Y}$. This means in a competition, athletes with previous ankle sprain can have another injury. However, due to the lack of studies looking at the effects of fatigue on sensory-motor control with previous injuries, the underlying mechanisms remain theoretical potential. Physical fatigue can change joint stability and joint laxity in healthy adults and it can create sensory-motor and biomechanical defects such as reduced muscle strength, activity, and internal deep sense and kinematics $(27,30)$. It is logical to assume that these factors will help to reduce the dynamic postural control, but the underlying mechanisms and the contribution of each of the components normally remain undisclosed.

No difference is shown in changes in postural control static related to fatigue between two groups. This result is contrary to observations by measuring the dynamic balance but it supports this argument that static and dynamic balance measurement of different aspects of control mechanisms can assess the different sensory-motor mechanism (31). If measuring the balance in one leg is considered, dynamic testing may be beneficial. But as they are more specific to the sport, it seems that there must be more sensitiveness in detecting sensory-motor deficits in the athlete population. We observed dynamic balance disorders in athletes with previous injuries. According our observations when participants were physically tired these disorders appear. These findings have direct implications for assessing and treating sports injuries. Education and training should be a key component of neuromuscular rehabilitation program, which aims to increase resistance against fatigue (32). In addition, when the stability of the joint and functional status is assessed after injuries, it may be helpful to perform tests in fatigue conditions for better decision making and returning to competition.

Table 1. Results of covariance analysis on the difference in outcome between the two groups after fatigue.

\begin{tabular}{|c|c|c|c|c|c|c|c|}
\hline \multirow[b]{2}{*}{ Variables } & \multicolumn{3}{|c|}{ Control } & \multicolumn{3}{|c|}{ Experimental } & \multirow[b]{2}{*}{$P$ value } \\
\hline & Pre-test & Post-test & Difference & Pre-test & Post-test & Difference & \\
\hline Romberg & $3.83 \pm 0.36$ & $4.74 \pm 0.43$ & $0.91(-0.52,-1.28)$ & $3.60 \pm 0.30$ & $4.14 \pm 0.29$ & $0.54(-0.35,-0.74)$ & $* 0.001$ \\
\hline Side jump & $6.89 \pm 1.09$ & $7.25 \pm 1.05$ & $0.36(0.53,-1.24)$ & $7.53 \pm 0.51$ & $8.23 \pm 0.58$ & $0.7(-1.63,-1.24)$ & $* 0.014$ \\
\hline Y Anterior & $74.76 \pm 5.08$ & $74.26 \pm 4.72$ & $-0.5(1.38,-0.38)$ & $73.12 \pm 3.14$ & $67.60 \pm 2.39$ & $-5.52(8.31,2.73)$ & $* 0.001$ \\
\hline Y posterior-internal & $85.57 \pm 3.84$ & $85.61 \pm 4.09$ & $0.04(0.21,-0.29)$ & $82.69 \pm 3.35$ & $75.73 \pm 3.54$ & $-6.96(7.27,6.64)$ & $* 0.001$ \\
\hline Y posterior-external & $80.51 \pm 5.24$ & $80.40 \pm 5.01$ & $-0.11(0.30,-0.06)$ & $77.13 \pm 3.19$ & $73.27 \pm 3.15$ & $-3.86(7.77,-0.05)$ & $* 0.003$ \\
\hline
\end{tabular}

*Marks a significant difference in the level of significance $\mathrm{P}<0.05$.

Table 2. Results of post hoc test to compare differences between experimental and control groups in terms of mean differences.

\begin{tabular}{lccccccc}
\hline Dependent ariables & Group (I) & Group $(\mathrm{J})$ & Mean difference (I-J) & Standard error & P value & Lower Bound & Upper Bound \\
\hline Romberg & Experimental & Control & -0.59 & 0.16 & $* 0.001$ & -0.93 & -0.25 \\
Side jump & Experimental & Control & 1.01 & 0.38 & $* 0.014$ & 0.22 & 1.81 \\
Y Anterior & Experimental & Control & -5.66 & 1.15 & $* 0.001$ & -8.05 \\
Y posterior-internal & Experimental & Control & -6.84 & 0.18 & $* 0.001$ & -7.22 & -3.27 \\
Y posterior-external & Experimental & Control & -5.46 & 1.60 & $* 0.003$ & -8.78 & -6.46 \\
\hline
\end{tabular}

*Marks a significant difference in the level of significance $\mathrm{P}<0.05$. 


\section{Discussion}

Based on results of this research, injuries were higher in players with a history of professional games. In addition, about half of all ankle injuries were associated with previous injuries which is normally occur in people with a history of the professional games. While it is expected that skilled players will have fewer injuries because of their skill and knowledge and having better techniques; but actually having more history in professional games means exposing to more injuries. On the other hand, high readiness level may lead to more contacts, more mobility and finally, increasing the risk of injuries (5). Another reason may be some injuries that are not completely untreated earlier. This can be seen in players with more history of games. As the results showed, the previous history of injuries in the professional game players was higher. McKay et al reported that more than half of ankle injuries in basketball were not treated professionally. They also commented that the history of previous ankle injuries in athletes has increased five-fold risk of injuries in future (12). So, encouraging players with ankle injuries to spend the whole period of treatment and rehabilitation is very important and can significantly reduce the risk of ankle injuries.

The results of this study can be concluded that one of the most common injuries in sports with prolonged walking, such as mountaineering is ankle injuries. This injury typically occurs while walking on hard and stony surfaces or while landing from a jump or sudden change of direction. Normally, skilled mountaineers and people with a history of previous ankle injury experience more injuries. That's why prevention of ankle injuries must be considered to reduce or minimize serious injuries.

One of the other most important causes of non-contact ankle sprain is joint instability and ligament laxity. Gharakhanlou mentioned to lack of physical fitness as the cause of $41 \%$ of the main injuries among elite Iranian athletes who are professional in karate(33). Akbari has mentioned to ankle sprain as the most common cause of ankle instability among athletes with long history of competitions (34). Zolfaghari mentioned to lack of ankle warm up as the most common cause of ankle sprain (35).

The results of this study showed that the nature of different sports can have an important effect on the structural characteristics of lower extremity injuries and also the severity of the injuries in athletes. The results show that the intensity of noncontact ankle sprain is higher in mountaineers. On the other hand, it seems that due to the high incidence of noncontact ankle sprain in the mountaineers it is necessary to focus on balance. Data from this study will be useful for athletes and coaches. Using these information and data help to prevent and reduce injuries, especially ankle injuries. By this way, athletes can benefit more from participating in physical activities (36).

Generally, based on the results of hypothesis testing, it can be concluded that athletes with a history of ankle sprain have some degree of functional impairments based on some factors such as severity of the initial injury, method of treatment, quality of rehabilitation program and so on. These defects can cause disturbances in their athletic performances. The recognition of these intangible impairments is important, especially at a professional level (37).

Using Romberg functional tests, side jump test and balance Y; all functional defects in relation to ankle injuries can be recognized very easily and without any re-injury. Then by determining the severity of defects, guidelines can be presented for preventing more ankle sprain. So, it can be possible to use these guidelines in pre- 
season tests and examinations to prevent more potential injuries (37).

As a result, the main usage of the result of this research is preventing more ankle sprains by identifying people of more risk factors and presenting injury prevention solutions. These tests in the field of rehabilitation and determine the amount of defects and affected persons disabilities and their amount of preparation to plan rehabilitation programs can be used more accurate. It is also possible to use these functional tests for determining the possible time for returning injured athletes to competition and practice.

The results of this study support our hypothesis that athletes with a history of lower extremity injury have some disturbances in postural control while they are fatigue in comparison with healthy athletes. There were differences between the affected group before fatigue and after fatigue in dynamic postural control which was higher than the control group. It seems

\section{References}

1. Garric JG. The frequency of injury, mechanism of injury, and epidemiology of ankle sprains. Am J Sports Med. 1977; 5(6):241-2.

2. Kofotolis N, Kellis E, Symeon P. Ankle sprain Injuries and Risk Factors in Amateur Soccer Players During a 2Year Period. Am J Sports Med. 2007; 35(3): 458-66.

3. Holmer P, Sondergaard L, Konradsen L, Nielsen PT, Jorgensen LN. Epidemiology of sprains in the lateral ankle and foot. Foot Ankle Int. 1994; 15(2): 72-4.

4. Freeman MA. Instability of the foot after injuries to the lateral ligament of the ankle. J Bone Joint Surg Br. 1965; 47(4): 669-77.

5. Kofotolis N, Kellis E. Ankle sprain injuries: a 2-years prospective cohort study in female Greek professional basketball players. J Athl Train. 2007; 42(3):388-94. continuous sensory-motor defects in athletes with previous injury will occult until they attend in a sport activity. When they are fatigue, injury will show the effects. These disorders may increase the risk of more injuries. Rehabilitation exercise programs need to consider this fact and should focus on endurance of neuromuscular and sensory-motor resistance. The interaction between physical fatigue and physical disability after injury needs further examination to obtain a better understanding of the underlying mechanisms. The difference in the results of static and dynamic control of the situation suggests that both aspects should be considered in a complex assessment. According to what was said, doctors, sports medicine specialists, physical therapists, athletic trainers and all the people who are linked athletes health can use these results in objectives such as the prevention, treatment and rehabilitation of ankle sprain injuries.

6. Alexander C. Exercise Physiology.3rd edition, Printed in United States of America. 1998; 226-9.

7. McCriskin $\mathrm{B}$, Cameron $\mathrm{K}$, Orr J, Waterman B. Management and prevention of acute and chronic lateral ankle instability in athletic patient populations. World J Orthop. 2015; (6) 2: 161-71

8. Lourok S, Weiss E. Burnnstorms clinical kinesiology. 4th ed. F.A Davis company.1983; 111-3.

9. Beynnon B, Murphy F, Alosa D. Predictive factors for lateral ankle sprains: a literature review. J Athl Train. 2002; 37(4):376-80.

10. Nelson A, Collins C, Yard E, Fields S, Comstock R. Ankle injuries among United States high school sports athletes. J Athl Train. 2007; 42(3):3817.

11. Fuller C, Ekstrand J, Junge A, Anderse T, Bahr R, Dvorak J. Consensus statement on injury definitions and 
data collection procedures in studies of football (soccer) injuries. Br J Sports Med. 2006; 40(3):193-201.

12. McKay G, Goldie P, Payne W, Oakes B. Ankle injuries in basketball: injury rate and risk factors. Br J Sports Med. 2001; 35(2):103-8.

13. Jackson D, Ashley R, Powell J. Ankle Sprains in Young Athletes: Relation of Severity and Disability. Clin Orthop Relat Res. 1974; 101(2):201-15.

14. Docherty C, Arnold B, Gansneder B, Hurwitz S, Gieck J. Functionalperformance deficits in volunteers with functional ankle instability. $\mathrm{J}$ Athl Train. 2005; 40(1):30-4

15. Lauren C, Christopher R, Hertel J, Sandra J. Efficacy of the star excursion balance tests in detecting reach deficits in subjects with chronic ankle instability. J Athl Train. 2002; 37(4): 501-6.

16. Sekir U, Yildiz Y, Hazneci B, Ors F, Aydin T. Effect of isokinetic training on strength, functionality and proprioception in athletes with functional ankle instability. Knee Surg Sports Traumatol Arthrosc. 2007; 15(5):654-64.

17. Munn J, Beard D, Refshauge K, Lee R. Do functional-performance tests detect impairment in subjects with ankle instability? J Sport Rehabil. 2002; 11(1): 40-50.

18. Kerry M, Sandra J, Docherty C, Gansneder B, Perrin D. Chronic Ankle Instability Does Not Affect Lower Extremity Functional Performance. J Athl Train. 2002; 37(4): 507-11.

19. Engebretsen A, Myklebust G, Holme I, Engebretsen L, Bahr R. Intrinsic risk factors for acute ankle injuries among male soccer players: a prospective cohort study. Scand J Med Sci Sports. 2010; 20(3):403-10.

20. Yim-Chiplis P, Talbot L. Defining and measuring balance in adults. Biol Res Nurs. 2000; 1(4): 321-31.
21. Reiman M, Manske R. Functional testing in human performance. USA: Human Kinetics; 2009; 155-59.

22. Ortiz A, Olson SL, Roddey T, Morales J. Reliability of selected physical performance tests in young adult women. J Strength Cond Res. 2005; 19(1): 39-44.

23. Gribble PA, Hertel J, Plisky P. Using the Star Excursion Balance Test to Assess Dynamic Postural-Control Deficits and Outcomes in Lower Extremity Injury: A Literature and Systematic Review. J Athl Train. 2012; 47(3): 339-57.

24. Plisky PJ, Gorman PP, Butler RJ, Kiesel K, Underwood FB, Elkins B. The reliability of an instrumented device for measuring components of the star excursion balance test. N Am J Sports Phys Ther. 2009; 4(2): 92-9.

25. Borg G. Perceived exertion as an indicator of somatic stress. Scand $\mathrm{J}$ Rehabil Med. 1970; 2(2):92-8.

26. Gribble PA, Hertel J, Denegar CR, Buckley WE. The effects of fatigue and chronic ankle instability on dynamic postural control. J Athl Train. 2004; 39(4):321-9.

27. Gandevia SC. Spinal and supraspinal factors in human muscle fatigue. Physiol Rev. 2001; 81(4):1725-89.

28. Forestier N, Teasdale N, Nougier V. Alteration of the position senseat the ankle induced by muscular fatigue in humans. Med Sci Sports Exerc. 2002; 34(1):117-22.

29. McLean SG, Fellin RE, Suedekum N, Calabrese G, Passerallo A, Joy S. Impact of fatigue on gender-based high-risk landing strategies. Med Sci Sports Exerc. 2007; 39(3):502-14.

30. Skinner HB, Wyatt MP, Stones ML, Hodgdon JA, Barrack RL. Exerciserelated knee joint laxity. Am J Sports Med. 1986; 14(1):30-4.

31. Gribble PA, Tucker WS, White PA. Time-of-day influences on static and dynamic postural control. J Athl Train. 2007; 42(1):35-41. 
32. Zech A, Hubscher M, Vogt L, Banzer W, Hansel F, Pfeifer K. Neuromuscular training for rehabilitation of sports injuries: asystematic review. Med Sci Sports Exerc. 2009; 41(10):1831-41.

33. Gharakhanlou R. [Evaluation of sports injuries from the perspective of experienced coaches and elite athletes]. Olymp J. 1999; 7(4):129-40.(Persian)

34. Akbari M, Ahanjan S, Akbari M. [The study of ankle instability in the national team athletes (wrestling, football and basketball). Sabzevar Faculty of Medical Sciences and Health Service]. 2007; 13 (4):178-84. (Persian)
35. Zolfagari R. [Prevalence and causes of injuries in elite athletes wrestling free high school in Mashhad. Master of Science Thesis in Physical Education and Sport Sciences]. 1997; 4-5. (Persian)

36. Erfani M, Sahebalzamani M, Marefati $\mathrm{H}$, Sharifian E. Evaluation of foot arch and its relationship with non-contact ankle sprain in athletes. J Sports Med, 2011; 3(1):99-112 .(Persian)

37. Babai H, Taheri HR, Qare MA, Bahrami M. [Evaluation of functional deficits in athletes with a history of ankle sprain]. J Lorestan Med Sci. 2008; 1(35): 37-46. (Persian) 